\title{
RESEARCH
}

Open Access

\section{Exploring features and function of Ss-riok-3, an enigmatic kinase gene from Strongyloides stercoralis}

Wang Yuan ${ }^{1}$, Yingying Liu', James B Lok ${ }^{2 *}$, Jonathan D Stoltzfus ${ }^{2,3}$, Robin B Gasser ${ }^{4}$, Weiqiang Lei ${ }^{1}$, Rui Fang ${ }^{1}$, Junlong Zhao ${ }^{1}$ and Min Hu${ }^{1 *}$

\begin{abstract}
Background: Right open reading frame protein kinase 3 (RIOK-3) belongs to the atypical kinase family. Unlike the other two members, RIOK-1 and RIOK-2, which are conserved from Archaea to humans, RIOK-3 occurs only in multicellular organisms. Studies on HeLa cells indicate that human RIOK-3 is a component of the 405 small ribosome subunit and supports cancer cell growth and survival. However, almost nothing is known about the function of RIOK-3. We explored the functional role of RIOK-3 encoding gene from Strongyloides stercoralis, a parasitic nematode of humans and dogs.
\end{abstract}

Methods: To analyze the gene and promoter structure of Ss-riok-3, RACE-PCR and Genome-walker PCR were performed to isolate the full length CDNA, gDNA and promoter region of Ss-riok-3. RNA-seq was conducted to assess the transcript abundance of Ss-riok-3 in different stages of $\mathrm{S}$. stercoralis. Transgenesis was employed to determine the anatomic expression patterns of Ss-riok-3.

Results: The RIOK-3 protein-encoding gene (designated Ss-riok-3) of S. stercoralis was characterized. The full-length complementary and genomic DNAs of the RIOK-3 encoding gene (riok-3) were isolated from this nematode. The cDNA of Ss-riok-3 is 1,757 bp in length, including a 23 bp 5'-UTR, a 36 bp 3'-UTR and a 1,698 bp coding region encoding a protein of 565 amino acids (aa) containing a RIO kinase domain. RNA sequencing (RNA-seq) analysis revealed that Ss-riok-3 is transcribed in all developmental stages of S. stercoralis assessed, with transcripts being particularly abundant in parasitic females. Gene structure analysis revealed that Ss-riok-3 contains no intron. The putative promoter contains conserved promoter elements, including four TATA, two GATA, one inverse GATA and one inverse CAAT boxes. The promoter of Ss-riok-3 drives GFP expression in the head neuron, intestine and body wall muscle of transgenic S. stercoralis larvae, and the TATA boxes present in the $3^{\prime}$-UTR of the gene immediately upstream of Ss-riok-3 initiate transcription.

Conclusions: The characterization of the RIOK-3 encoding gene from S. stercoralis provides a sound foundation for investigating in detail its function in the development and reproduction of this important pathogen.

Keywords: Parasitic nematode, Strongyloides stercoralis, riok-3, Transgenesis

\footnotetext{
*Correspondence: jlok@vet.upenn.edu; mhu@mail.hzau.edu.cn

${ }^{2}$ Department of Pathobiology, School of Veterinary Medicine, University of

Pennsylvania, 3800 Spruce Street, Philadelphia, PA 19104, USA

'State Key Laboratory of Agricultural Microbiology, Key Laboratory of

Development of Veterinary Diagnostic Products, Ministry of Agriculture,

College of Veterinary Medicine, Huazhong Agricultural University, 1 Shizishan

Street, Wuhan 430070, China

Full list of author information is available at the end of the article
}

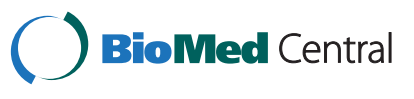

(c) 2014 Wang et al.; licensee BioMed Central. This is an Open Access article distributed under the terms of the Creative Commons Attribution License (http://creativecommons.org/licenses/by/4.0), which permits unrestricted use, distribution, and reproduction in any medium, provided the original work is properly credited. The Creative Commons Public Domain Dedication waiver (http://creativecommons.org/publicdomain/zero/1.0/) applies to the data made available in this article, unless otherwise stated. 


\section{Background}

Strongyloides stercoralis is a parasitic nematode of humans and dogs, affecting estimated 60-100 million people worldwide and causing strongyloidiasis [1]. The life cycle of $S$. stercoralis is more complicated than those of most obligatory parasitic nematodes. Parasitic females (P Female) live in the intestine of the host and reproduce by mitotic parthenogenesis. They lay sexually differentiated eggs; these eggs hatch in the intestine, and post-parasitic firststage larvae (PP L1) are either passed in the feces, or develop directly to auto-infective L3 (aiL3) within the host intestine. Then aiL3 invade somatic tissues and return to the intestine to produce a new generation of parasitic female adults (P Female). S. stercoralis undergoes low levels of autoinfection in immuno-competent hosts, however this process of autoinfection may proceed for sequential generations in an immuno-compromised host, with geometric expansion of parasite numbers and involvement of multiple body tissues, possibly leading to a fatal outcome [2]. In immune-competent hosts, PP L1 pass in feces from the host, and female PP L1 develop either homogonically to infective third-stage larvae (iL3) or heterogonically to freeliving female adults (FL Female), whereas the male PP L1 develop to free-living male adults (FL Male) invariably. The FL Female and FL Male mate and produce embryos, which develop to iL3 through post free-living L1 (PFL L1); iL3 infect the host by skin penetration and develop to $\mathrm{P}$ Female [2].

The complex life cycle of $S$. stercoralis and lack of knowledge about its developmental biology has hampered the progress to control strongyloidiasis, requiring us to elucidate key biological processes in the development. Studies of the essential molecules that regulate the development of parasitic nematodes, including $S$. stercoralis, could facilitate the discovery of new interventions to control strongyloidiasis and other nematodiases.

One group of molecules essential in eukaryotic organisms is the protein kinases. Such kinases are key enzymes required for the regulation of a wide range of cellular processes, including cell-cycle progression, transcription, DNA replication and/or metabolic processes [3]. Based on their kinase domain sequences, protein kinases can be classified as eukaryotic protein kinases (ePKs) and atypical protein kinases (aPKs). In the human genome, 13 aPK families have been defined thus far, and one of them represents the family of the RIO protein kinases [4]. Four members of the RIO protein kinase family have been reported, i.e. RIOK-1, RIOK-2, RIOK-3 and RIOK-B. RIOK-1 and RIOK-2 are conserved from Archaea to humans, whereas RIOK-3 is only present in multicellular eukaryotes and, interestingly, RIOK-B is found in some bacteria [5]. RIOK-1, RIOK-2 and RIOK-3 contain a conserved RIO domain comprising multiple conserved functional motifs [5]. However, the sequences of these motifs differ among the three RIO kinases with the RIO domain of RIOK-1 and RIOK-3 being more similar in sequence. External to their RIO domain, RIOK-2 and RIOK-3 contain an N-terminal domain which is absent from RIOK-1 [6]. Consistent with these structural differences, the functions of the eukaryotic RIO kinases are also different. Although both RIOK-1 and RIOK-2 are involved in the maturation of the $40 \mathrm{~S}$ ribosomal subunit including rRNA maturation and recycling other trans-acting factors involved in the maturation of $40 \mathrm{~S}$ subunit, their functions therein are different, and they do not complement each other in yeast and human cells [7-9].

The function of RIOK-3 appears to diverge markedly from those of RIOK-1 and RIOK-2. In spite of the report that human RIOK-3 is also a component of $40 \mathrm{~S}$ ribosomal subunit particles, its function in ribosomal synthesis is still unknown [10]. Human RIOK-3 is over-expressed in cancer cells [11-13] and interacts with caspase-10 to downregulate NF- $\mathrm{kB}$ signaling by competing with receptorinteracting protein 1 (RIP1) and NF-kB-inducing kinase (NIK) [14]. These findings suggest that RIOK-3 is necessary for human cancer cell growth and survival [13-15]. In spite of the functional importance of RIOK-3 in human cells, nothing is known about the function of this molecule in nematodes, except for the early studies from RNAi screens in free-living nematode Caenorhabditis elegans [16-18], which have revealed no visible phenotypes including embryonic and larvae lethal, embryonic development variant, larvae developmental arrest, maternal sterile, organism morphology variant for the gene Ce-riok-3 (data from WormBase, http://www.wormbase.org/\#01-23-6). This information suggests that the function of Ce-riok-3 in C. elegans is redundant. Whether riok-3 function can be replaced and/or supported by other genes in parasites is still unknown.

Although RNAi is an efficient tool for the analysis of gene function in C. elegans, this approach does not work well in parasitic nematodes of animals studied to date [19]. Without effective RNAi-based methods, transgenesis constitutes an alternative approach for the functional genomic analysis of parasitic nematodes such as S. stercoralis [20-23]. In the present study, we explored RIOK-3 encoding gene Ss-riok-3 of S. stercoralis, and investigated its temporal and spatial expression patterns towards the ultimate goals of uncovering its function and understanding its role in S. stercoralis.

\section{Methods}

\section{Ethics statement}

The S. stercoralis (UPD strain) was maintained in prednisolone-treated Beagles, in accordance with a protocol (permit no. SYXK-0029) approved by the Animal Ethics and Animal Experimentation Committee of Hubei Province. The care and maintenance of dogs were in strict accordance with the regulations for the 
Administration of Affairs Concerning Experimental Animals of P. R. China.

\section{Parasite maintenance and culture}

The UPD strain of $S$. stercoralis was maintained in immune-suppressed dogs [24]; iL3 were collected from 7-10 day-old copro-cultures $\left(22^{\circ} \mathrm{C}\right)$ via Baermann funnel and washed with sterile buffered saline (BU) [24-26]. Freeliving adults of $S$. stercoralis were collected via Baermann funnel from copro-cultures after 2 days of incubation at $22^{\circ} \mathrm{C}$ and then were placed on nematode growth medium (NGM) plates and maintained on Escherichia coli OP50.

\section{Preparation of nucleic acids}

Nucleic acids were isolated from 10,000-20,000 iL3s by a small-scale sodium proteinase K extraction [27] followed by purification using a mini-column (Wizard DNA Clean-Up System, Promega, USA). RNA was extracted from 20,000 30,000 iL3s using by TRizol reagent extraction (Life Technologies, USA). RNA yields were estimated spectrophotometrically (NanoDrop Technologies, Thermo Scientific, USA), and $1 \mu \mathrm{g}$ of RNA was reverse transcribed to cDNA using a kit (Smart RACE Kit, Clontech, USA). Nucleic acids were stored at $-80^{\circ} \mathrm{C}$ (RNA) or $-20^{\circ} \mathrm{C}$ (DNA) until use.

\section{Isolating CDNA and promoter elements of Ss-riok-3}

Two primers $1 \mathrm{~F}$ and $2 \mathrm{R}$ (Additional file 1) were designed to the sequences of three expressed sequence tags (ESTs) for Ss-riok-3 (GenBank accession nos. BE224215, BE223756.1 and BG224329.1) from National Center for Biotechnology Information (NCBI, http://www.ncbi.nlm. nih.gov/). Using this primer pair, a region (255 bp) was PCR-amplified from cDNA transcribed from total RNA from iL3s of S. stercoralis, T/A-cloned into the vector pMD19T (Takara Biotechnology, Dalian, China) and directly sequenced. Based on the sequence obtained, genespecific primers ( $3 \mathrm{~F}$ and $4 \mathrm{R}$ ) were designed (Additional file 1). Using this pair of gene-specific primers and adaptor primers (from the RACE Amplification Kit, cat. no. 634923, Clontech), two partially overlapping cDNA fragments were produced from total RNA of $S$. stercoralis by 5 '- and 3'-RACE, respectively. After sequencing the two partial cDNAs, three gene-specific primers $(5 \mathrm{~F}, 6 \mathrm{R}$ and 8R) were designed to amplify the 5'- and 3'-termini of the Ss-riok-3 cDNA (Additional file 1). The complete cDNA of Ss-riok-3 was assembled using the sequences derived from the 5'-RACE and 3'-RACE amplicons and was searched and compared with the S. stercoralis genomic contigs (6 December 2011 draft; ftp://ftp.sanger.ac.uk/ pub/pathogens/HGI/) by Geneious version 5.5.6 (http:// www.geneious.com/). Subsequently, a pair of primers with restriction sites (Ss-riok3-EcoRI, Ss-riok3-HindIII) was designed to PCR-amplify the coding sequence (CDS) of Ss-riok-3 using the Advantage 2 Polymerase Mix (Clontech), employing the following cycling conditions: initial $94^{\circ} \mathrm{C}$, $5 \mathrm{~min}$; then $94^{\circ} \mathrm{C}, 30 \mathrm{~s}, 55^{\circ} \mathrm{C}, 30 \mathrm{~s} ; 72^{\circ} \mathrm{C}, 90 \mathrm{~s}$ for 30 cycles; final extension at $72^{\circ} \mathrm{C}, 10 \mathrm{~min}$. The resultant amplicon was then (T/A) cloned into pMD19-T and sequenced.

To identify the Ss-riok-3 promoter, four genomic DNA libraries were constructed using the Genome-Walker Kit (cat. no. 638904, BD Bioscience, Clontech) following the manufacturer's instructions. Briefly, genomic DNA was digested with each of four restriction enzymes DraI, EcoRV, PvuII and StuI (BD Biosciences, Clontech). Each of the four digested products was purified by phenol/chloroform extraction and then linked to an adapter with T4 DNA ligase. Then, PCR was performed using one adapter senseprimer and one gene-specific antisense-primer 10R (Additional file 1). All PCRs were conducted using the BD Advantage 2 Polymerase Mix (cat. no. 639201, Clontech) using the recommended touch-down PCR cycling protocol: 7 cycles at $94^{\circ} \mathrm{C}, 25 \mathrm{sec} ; 72^{\circ} \mathrm{C}, 3 \mathrm{~min} ; 32$ cycles at $94^{\circ} \mathrm{C}, 25 \mathrm{sec}, 67^{\circ} \mathrm{C}, 3 \mathrm{~min}$; final extension at $67^{\circ} \mathrm{C}$ for $7 \mathrm{~min}$. The amplicons from all four genomic DNA libraries were examined separately on agarose gels; the largest products were purified employing TIANGEN Gel DNA purification kit (Tiangen Biotech, Beijing, China) and then (T/A) cloned into the vector pMD19-T (Takara Biotechnology) for subsequent sequencing.

To isolate the 3' UTR of Ss-riok-3 upstream gene (Ss-rep-1), the 3'-RACE was performed with one gene specific sense primer (Ss-rep1-3 F, Additional file 1) and the adapter primer (RACE Amplification Kit, Clontech). The sense primer Ss-rep1-3 F was designed based on the sequence obtained by Genome-Walker PCR. 3'-RACE PCR was performed using the Advantage 2 Polymerase Mix (Clontech) with following protocol: initial $94^{\circ} \mathrm{C}, 5 \mathrm{~min}$; then $94^{\circ} \mathrm{C}, 30 \mathrm{~s}, 55^{\circ} \mathrm{C}, 30 \mathrm{~s} ; 72^{\circ} \mathrm{C}, 90 \mathrm{~s}$ for 30 cycles; final extension at $72^{\circ} \mathrm{C}, 10 \mathrm{~min}$. The PCR product was (T/A) cloned into pMD-19 T and sequenced. After confirming the end of the 3' UTR of Ss-rep-1 by aligning the cDNA with gDNA, two sense-primers, Ss-riok3pro1-HindIII and Ss-riok3pro2-HindIII and one anti-sense primer Ssriok3pro-SmaI (Additional file 1) were designed to isolate the promoter region of $S s$-riok-3, and the anti-sense primer Ss-riok3pro-SmaI was designed downstream (374 bp) of the start codon of Ss-riok-3 and positioned according to the 91 nucleotides including a $42 \mathrm{bp}$ artificial intron (see Additional file 2) between SmaI restrict site and the start codon of $g f p$ of the promoter-less plasmid pAJ 02, in order to match the codon order. Each of the two sense-primers was used with their respective anti-sense primer to PCRamplify 683 bp or 881 bp of genomic DNA upstream of Ss-riok-3 (Additional file 2). The following cycling protocol was used: initial at $94^{\circ} \mathrm{C}$ for $3 \mathrm{~min}$; then $94^{\circ} \mathrm{C}, 30 \mathrm{~s} ; 72^{\circ} \mathrm{C}$, $3 \mathrm{~min}$ for 5 cycles, followed by $94^{\circ} \mathrm{C}, 30 \mathrm{~s} ; 67^{\circ} \mathrm{C}, 3 \mathrm{~min}$ for 25 cycles, and a final extension of $67^{\circ} \mathrm{C}, 7 \mathrm{~min}$. Each amplicon was then (T/A) cloned into PMD19-T for sequencing. 


\section{Bioinformatic analyses}

The cDNA sequence of Ss-riok-3 was compared with publicly available sequence data in non-redundant databases from NCBI (http://www.ncbi.nlm.nih.gov/) using BlastX [28]. The Ss-riok-3 cDNA was translated into a predicted amino acid (aa) sequence (Ss-RIOK-3) using the program BioEdit (http://www.mbio.ncsu.edu/BioEdit/bioedit.html\# downloads). Protein motifs of Ss-RIOK-3 were predicted by interrogating the databases PROSITE [29] (www.expasy. ch/tools/scnpsit1.html) and Pfam [30] (www.sanger.ac. $\mathrm{uk} /$ Software/Pfam/). The sequence of Ss-RIOK-3 and its homologs from selected species were aligned using the program MAFFT 7.0 [31] (http://mafft.cbrc.jp/alignment/ software/). The functional domains and sub-domains were then identified in aligned RIOK3 sequences and then highlighted using the program Photoshop CS v.5.0.

The genomic sequence upstream of Ce-riok-3 was retrieved from WormBase (WS243, http://www.wormbase. org/); promoter elements of Ss-riok-3 and Ce-riok-3, and their respective upstream genes were predicted using the transcription element search system MatrixCatch (http:// www.gene-regulation.com/cgi-bin/mcatch/MatrixCatch.pl) [32]. The two putative promoter sequences were aligned using MAFFT 7.0 [31].

For phylogenetic analysis, $S s$-RIOK-3 was searched in the non-redundant database of NCBI (http://www.ncbi.nlm. nih.gov/) and 18 homologous sequences were retrieved from six nematodes [Ascaris suum (ERG84434.1), Caenorhabditis brenneri (EGT33672.1), C. elegans (NP_499173.1), C. remanei (XP_003113164.1), Haemonchus contortus (ADW27446.1), Loa loa (XP_003136543.1)]; two arthropods [Aedes aegypti (XP_001660046.1) and Drosophila melanogaster (AAF50965.1)]; nine vertebrates [Canis lupus familiaris (XP_005623064.1), Danio rerio (NP_ 001003614.1), Homo sapiens (NP_003822.2, EAX01152.1), Mus musculus (NP_077144.2), Pan troglodytes (XP_ 003953313.1), Rattus norvegicus (NP_001101893.1), Salmo salar (NP_001133982.1), Xenopus laevis (NP_001083392.1) and X. tropicalis (NP_001004996.1)]; and yeast [Schizosaccharomyces pombe (CAA15723.2)]. Sequences of these 18 RIOK-3 homologs were then aligned with that of Ss-RIOK-3 using Clustal $\mathrm{X}$ and manually adjusted. Phylogenetic analyses were conducted using the maximum likelihood (ML), maximum parsimony (MP) and neighbor-joining (NJ) methods based on the Jones-Taylor-Thornton (JTT) model in the software package MEGA v.5.0 [33]. Confidence limits were assessed by bootstrapping using 1,000 pseudoreplicates for ML, MP and NJ; other settings were obtained using the default values in MEGA v.5.0 [33]. A 50\% cut-off value was implemented for the consensus tree.

\section{Transcriptional analysis}

The S. stercoralis (PV001 line), derived from a single female worm of the UPD strain, was maintained as described previously [24,34-37]. Transcription profiles of Ss-riok-3 were assessed in seven developmental stages of the PV001 line of S. stercoralis, including free-living females (FL Female), post-free-living first-stage larvae (PFL L1), infective third-stage larvae (iL3), in vivo activated third-stage larvae (L3+), parasitic females (P Female), post-parasitic first-stage larvae (PP L1) and post-parasitic third-stage larvae (PP L3). The parasites from different stages were isolated as described previously [34,35]. Transcription was quantified using RNA-seq [35]. Raw RNA-seq data for the seven developmental stages are available at http://www. ebi.ac.uk/arrayexpress/ under accession numbers E-MTAB2192 (iL3) and E-MTAB-1164 (FL Female, PFL L1, L3+, P Female, PP L1, and PP L3). Ss-riok-3-specific transcript abundances were calculated as fragments per kilobase of coding exon per million fragments mapped (FPKM), and significant differences in FPKM values between developmental stages were determined using Cufflinks v.2.0.2 (http://cufflinks.cbcb.umd.edu/) [35,38-40]; $p$-values $<0.05$ were considered statistically significant, and $p$-values $<0.001$ were considered statistically highly significant. FPKM and 95\% confidence intervals were plotted in Prism version 5.01 (GraphPad Software, Inc., http://www.graphpad.com/).

\section{Transformation constructs and transformation of \\ S. stercoralis}

To make reporter transgene constructs, alternative promoter regions of Ss-riok-3 (Additional file 2), $683 \mathrm{bp}$ and $881 \mathrm{bp}$, respectively, were digested with the endonucleases Hind III and Sam I (Thermo Fisher Scientific, USA) from the (T/A) cloned recombinant pMD19T plasmids and gelpurified using the Tiangen Gel Purification Kit (Tiangen Biotech). Each of the purified products was then subcloned into the promoter-less plasmid pAJ 02 [41], upstream of the $g f p$ CDS, to create two plasmids: pRP2: Ss-riok-3p (683 bp)::gfp::Ss-era-1 3'-UTR and pRP4: Ss-riok-3p (881 bp)::gfp::Ss-era-1 3'-UTR (Additional file 2). The inserts of the plasmids were sequenced. After confirming the sequences, the two constructs were isolated using the TIANpure Midi Plasmid Kit (Tiangen Biotech) and each of them was diluted to $50 \mathrm{ng} / \mu \mathrm{l}$ and stored at $-20^{\circ} \mathrm{C}$. FL Females were transformed by gonadal microinjection as previously described [23]. Briefly, solutions containing $50 \mathrm{ng} / \mu \mathrm{L}$ of plasmid $\mathrm{pRP} 2$ or $\mathrm{pRP} 4$ were injected into the gonads of FL Females. Transformed FL Females were then paired with one or two FL adult male (s) on an NGM + OP50 plates, and incubated at $22^{\circ} \mathrm{C}$ for subsequent egg laying. F1 post-free-living progeny were screened for fluorescence at 24, 48 and $72 \mathrm{~h}$, respectively, after microinjection. S. stercoralis larvae were screened for expression of fluorescent reporter transgenes using a stereomicroscope (SZX12, Olympus) with epifluorescence. Then the S. stercoralis worms with GFP expression were placed on $2 \%$ agarose pad (Lonza, Basel, Switzerland), 


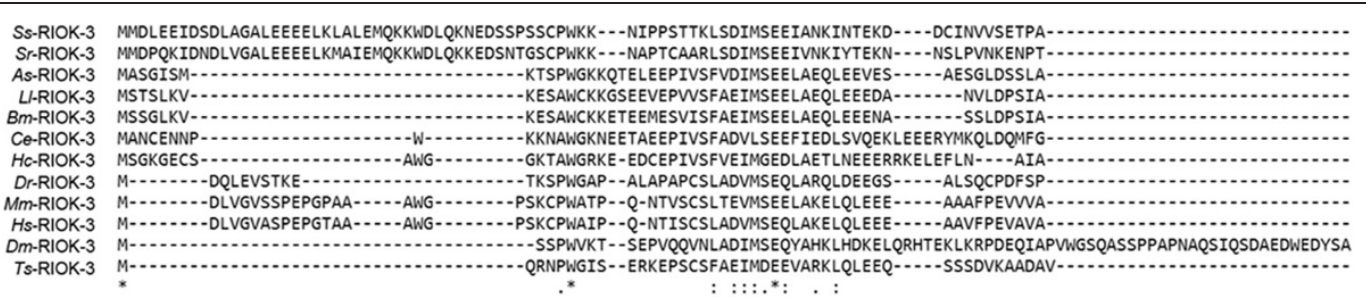

SS-RIOK-3 -..-TVTLPNWVE---EEMDPDLKLALELQKQFDAEVSLDDTDFEEAKKLQKIFDEEVAQIYDKDHSLDIS-EAKKLQHEWDMEVLNKESPKSITFGMTRY-.....--KFSHDDEIDDYEAL Sr-RIOK-3 -..-TITLPIEEV---EEMDPDLKLAMELQKQFDAELSIDDTDREEALRLQKIFDEEIAQIYDKDHSLDIS-EAKKLQHEWDIEVLNEESPKPITFGMTRY-....--KF SHDDEVDDYDAL

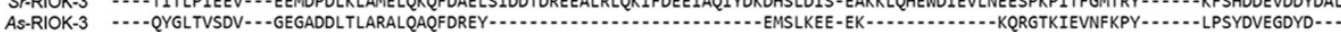

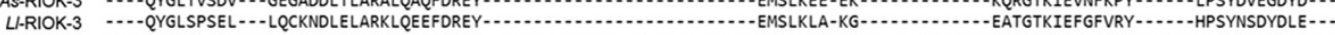

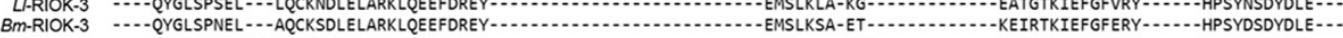

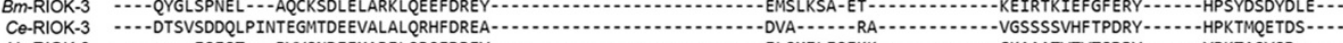
CO-RIOK-3

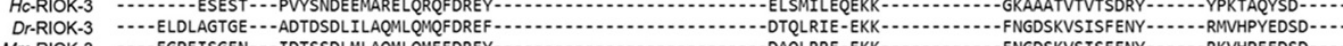

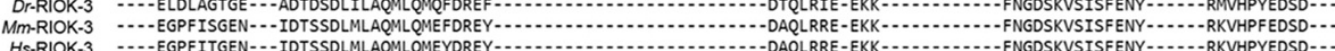
HS-RIOK-3 $\quad \ldots-$ EGPFITGEN - - IDTSSDLMLAQMLQMEYDEY $-\ldots$

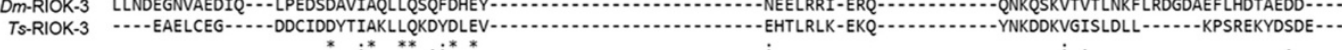
:.

SS-RIOK-3 LDEY-DEEDIKEKSWLKKY--EKKDNFIGDND---NVKNDCNFT-TKHD-.--TELSKIRNADKTMNFAIGMNIGDCSD--EKISNKVFNKLRQYSKDEIKRHFKIKDKAEKSTYEQGMDE Sr-RIOK-3 LQEYEDEEDIKEKSWIKKY--EKKDNFLGDND---INKNDCVAT-TKHD-..--TELAKIRNADKTMNFAIGMNIGDCSD--EKISNKVFNKLRQYSKDEIKRNFKIKDKAEKSTYEQGMDE As-RIOK-3 EESSEDDEDIRELATNLFY--ENVKEEFPPCG--FVKDAEGNVI-TKHD-..--KEVMERRNTNKVMQLPIDFPTGDWVG--EKLSDRVFNTLRAYSKTDQKRNIRVKDKEEKAISEQSMDA LI-RIOK-3 EELSEDDEDLREIAIDFVY--SRTKDEFPPSG--YMRNASGHLI-TKHD--.-KEIAERRNSEKVMHLPINIPTGDWG--ERLSNRVYNKLRNYGKVDQRRNAREKDKDEKATNELSMDK BM-RIOK-3 EELSEDDEDLREVAIDFLY--SRPKDEFPSSG--YMRDGSGHLI-TKHD----KEIAERRNSEKVMHLPIDIPTGDVG--EKLSNRVYNKLRNYCKTDQRRNARVKDKDEKATNELSMDK C $\theta-R I O K-3$--ENEDDDALRQAATDMLY--AKLDEENATNS--RLRPEGPSTSRTKHD-..--TGVSGRRNADKTFNDRNTLPTGDMVG--DKLNNKVFNKLMAFGKSESKRQMRNKDKEEKATMDTSVDS Hc-RIOK-3 --VSSDDEDVROFATDLYY--AKLTDDVPSHSGPVFRNAGGDLV-TKHD-..-ANVSARRNADKAMNDKVNLAFGDMNO- - EOISSRVENSLRNESKSETKRLHKLKDKEKATIETSMD Dr-RIOK-3 --SSEDEVDWODTRHDPYR--AVKPTTTPKKG-.--FVGKGKNIT-TKHD-.--EEICGRKNTARMDNFAPEVHVGDGIGMDLKLSNOVYNALKRHCOTEORRSARLHEKKEHSTAEOAVDP Dr-RIOK-3 - --SSEDEVDWDTRDDPYR --PAKPIPTPKKG -..-FIGKGKDIT-TKHD-..-EVWCGRKNTARMENFAPGFOVGDGIGMDLKLSNHVFNALKOHAYSEERRSARLHEKKEHSTAEKAVDP Hs-RIOK-3 - --SSEDEVDWODTRDDPYR --PAKPVPTPKKG-..-FIGKGKDIT-TKHD-...-EVWCGRKNTARMENFAPEFOVGDGIGMDLKLSNHVFNALKOHAYSEERRSARLHEKKEHSTAEKAVDP

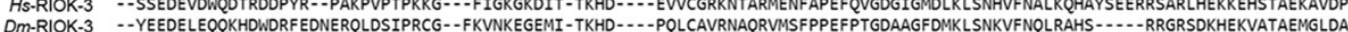
Ts-RIOK-3 SVEERDDEELE-..................

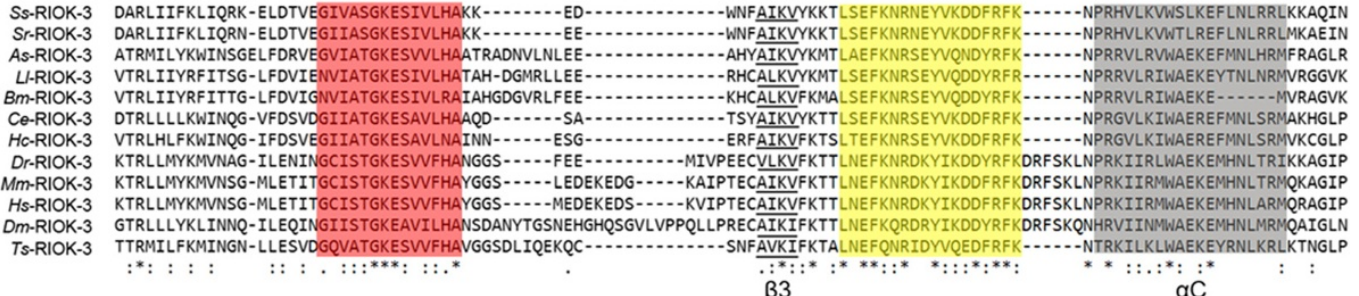

Hinge

Active site Metal binding loop $\begin{array}{ll}\text { SS-RIOK-3 } & \text { APEPLYVKKNVLVMRMIGEDK-PALKLKDVVFQ---DEESKELAYQKVENIICEMYKNCKLVHGDLSEFNLLYN-KGIIYVIDVSOAMDLSHPNSLVFLLRDIENILNFFNTTGTPNLPSS } \\ \text { S } r \text {-RIOK-3 } & \text { APEPLYVKKNVLVMRMIGEDK-PALKLKDVLFQ---DEESKELAFKMVEKIICDMYKNCKLVHGDLSEFNLLYH-KGVIYVIDVSOAMDLSHPNSLVFLLRDIENILNFFNSIGTONLPSS }\end{array}$ Sr-RIOK-3 APEPLYVKKNVLVMRMIGEDK-PALKLKDVLFQ---DEESKELAFKMVEKIICDMYKNCKLVHGDLSEFNLLYH-KGVIYVIDVSQAMDLSHPNSLVFLLRDIENILNFFNSIGTQNLPSS As-RIOK-3 CPEPIRLRRHVMMMLIGSGGRAAPKLKSIEWE---DQESKADAFQQVREAMSRMFKECRLVHGDLSEFNILYH-LGHAYIIDVSQAIDVSHPRSLFFLLRDIENVLEYFGRVGTEELPSA LI-RIOK-3 CPKPIRLRKHIMIMTFIGSNGIAARKLKDIEWS---DQEIIYNTFLQVKAEMIKMFTNCNLVHGDLSEFNVLYH-ESDVYIIDVSQAMDISHPRALFFLLRDVDNVLEFFAKLGAKNLPSA Bm-RIOK-3 CPKPIRLRKHIMIMTFIGSNGIAARKLKDIEWI---DQEIIYDTFLQVKEAMIKMFSDCNLVHGDLSEFNILYH-ENDVYIIDVSQAMDISHPRALFFLLRDINNVLEFFGKLGTKNLPSA Ce-RIOK-3 CPQPVKVRRNVLVMSFLGDQGLAAPRLKNVEWEFFTDDE-RRNVYDQVQSIMCRMYKECLLVHADLSEFNLLLTPDNKVHVIDVSQAMDLSHPRSLQFLLTRDIQNIITFFTRIGTPNLPTY HC-RIOK-3 CPVPVKLKRHLLLLMSIIGENGAAAPRLKNIDWEFSTIEE-RKDIFSQVIDIMNRMYRDCRLVHGDLSEFNLLLS-EGKVYVIDVSQSMDLSHPRNLHFLIRDIENVLAFFQRLDIPELPTP Dr-RIOK-3 CPEWILKKHILVMSFIGKDHAPAPKLKDAILN---SED-MKNAYYQVLNMMQRLYQDCNLVHADLSEYNMLWH-DRQVWFIDVSQSIEPTHPHGLEFLFRDCRNVATFFQKAGVAEAFNV Mm-RIOK-3 CPTVVLLKKHILVMSFIGHDQVPAPKLKEVKLS---NEE-MKDAYYQTLHLMQQLYNECTLVHADLSEYNMLWH-AGKVWLIDVSQSVEPTHPHGLEFLFRDCRNVSQFFQKGGVTEALN Hs-RIOK-3 CPTWLLKKHILVMSFIGHDQVPAPKLKEVKLN---SEE-MKEAYYQTLHLMRQLYHECTLVHADLSEYNMLWH-AGKVWLIDVSQSVEPTHPHGLEFLFRDCRNVSQFFQKGGVKEALSE DM-RIOK-3 VPDWVLKKHVLVMRFIGDNHNAAPKLKDARLS---DAE-LSCAYEEIVAMMHKLYNEAKLVHADMSEYNILWF-EGKCWFIDVAQSVEPKHPSALEFLMRDCGNIVNFFERRGLPNIYTK

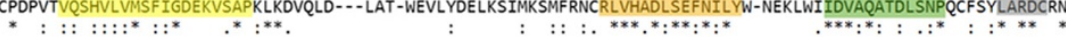

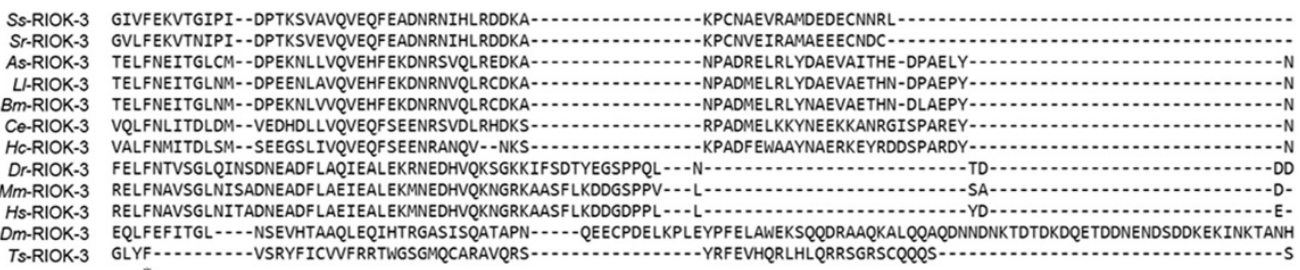

Figure 1 (See legend on next page.) 
(See figure on previous page.)

Figure 1 Alignment of the inferred amino acid sequence of Strongyloides stercoralis Ss-RIOK-3 with those of RIOK-3 s from 12 other species of eukaryote. The species selected were Strongyloides ratti (GCA_000208845.1, Sr-RIOK-3), Ascaris suum (ERG84434.1, As-RIOK-3), Loa loa (XP_003136543.1, LI-RIOK-3), Brugia malayi (XP_001899758.1, Bm-RIOK-3), Caenorhabditis elegans (NP_499173.1, Ce-RIOK-3), Haemonchus contortus (ADW23594.1, Hc-RIOK-3), Danio rerio (NP_001003614.1, Dr-RIOK-3), Mus musculus (AAH33271.1, Mm-RIOK-3), Homo sapiens (NP_003822.2, Hs-RIOK-3), Drosophila melanogaster (AAF50965.1, Dm-RIOK-3), Trichinella spiralis (XP_003372228.1, Ts-RIOK-3). Alpha-helices (A-l) are highlighted in light grey; beta-sheet structures are marked under the alignment. Functional motifs, including the ATP-binding motif (red), the flexible loop (yellow), the hinge (yellow), the active site (orange) and the metal binding loop (green), are highlighted and labeled above the alignment. Identical residues are marked with asterisks.

anesthetized using $50 \mathrm{mM}$ levamisole (Sigma-Aldrich, USA) to examine in detail using a compound microscope (BX60, Olympus) with Nomarski Differential Interference Contrast (DIC) optics and epifluorescence. Larvae were imaged with a Spot RT Color digital camera and Spot Advanced image analysis software (Diagnostic Instruments Inc., USA). Captured images were processed using Photoshop CS v.5.0 as previously described [42]. Imageprocessing algorithms, limited to brightness and contrast adjustments, were all applied in linear fashion across the entire image.

\section{Results}

\section{Characterization of Ss-riok-3 cDNA}

The full-length cDNA of Ss-riok-3 is 1,757 bp in length comprising a 23 bp 5'-UTR, a 36 bp 3'-UTR and a 1698 bp coding sequence encoding 565 aa. A poly A tract, followed the 3'-UTR and the polyadenylation signal (AAUAAA) was found at the eighteenth nucleotide from the poly A tail. The predicted Ss-RIOK-3 protein exhibits low sequence identities (21.4-37.5\%) to RIOK-3 s from various organisms, including other nematodes, fish, amphibians, vertebrates, with the highest identity (37.54\%) being to As-RIOK-3 (ERG84434) from A. suum.

The predicted aa sequence of Ss-RIOK-3 was aligned to homologs from 11 selected species, including seven nematode and four non-nematode species (Figure 1). The alignment showed that Ss-RIOK-3 contained a conserved RIO domain, including the ATP binding motif (P-loop), the flexible loop (which is unique in RIOK family), the hinge region, the active site and the metal binding motif (DFG-loop). The peptide sequence representing the ATP binding motif of RIOK-3 is STGKES. Interestingly, the ATP binding motif of RIOK-3 s from nematodes aligned here have Ala (A), instead of Ser (S), at the first position; in addition, Thr $(\mathrm{T})$ was a Ser $(\mathrm{S})$ at the second position in both Ss-RIOK-3 and RIOK-3 of Strongyloides ratti (Sr-RIOK-3). The predicted active site (catalytic loop) sequence of RIOK-3 s, LVH(G/A)DLSE $(\mathrm{F} / \mathrm{Y}) \mathrm{N}$, also varies at the fourth aa and ninth aa among distinct species. With the exception of Trichinella spiralis (Ts-RIOK-3), the parasitic nematodes studied herein have a Gly (G) at the fourth position instead of Ala (A), as seen in fish, mammals and the free-living nematode C. elegans.
Another aa alteration occurred at the ninth aa in the predicted active site; all nematodes selected here have a Phe (F), whereas the RIOK-3 s from fish, insects and mammals have a Tyr (Y) at this position. The Asp (D) at the fifth position in the active site, which is associated with kinase activity, is identical among the species studied and is conserved across known ePKs $[3,43]$. The sequence alignment (Figure 1) also highlights that Ss-RIOK-3 and Sr-RIOK-3 contain a larger $\mathrm{N}$-terminal region compared with RIOK$3 \mathrm{~s}$ from other species studied here. This divergence in the $\mathrm{N}$-terminus reflects the low identity between Strongyloides RIOK-3 s and their homologs in other taxa.

\section{Evolutionary relationship of the predicted protein Ss-RIOK-3 to homologs from other species}

Results of phylogenetic analyses revealed that there is concordance in topology among ML, MP and NJ trees (Figure 2). RIOK-3 s from seven nematodes, including Ss-RIOK-3, grouped together with high nodal support (100\%). Ss-RIOK-3 had the closest relationship to the RIOK-3 s from parasitic nematodes of clade III [44] with moderate support (77\%). Another large cluster containing RIOK-3 s from six mammals, two amphibians, two fish and two insects grouped together with high bootstrap support (98\%). RIOK-3 s from two species of amphibian and two species of fish grouped with the RIOK-3 s from six mammalian species with strong support (100\%). RIOK-3 s of two insect species grouped together with strong nodal support (100\%).

\section{Characterisation of the organization of the gene Ss-riok-3}

Comparison of cDNA and genomic DNA sequences of Ss-riok-3 revealed that there are no introns in the coding sequence of this gene or in its untranslated regions (Figure 3). Comparison of gene structures between Ss-riok-3 and two homologs, Ce-riok-3 from C. elegans (ZK632.3 from WormBase) and Hc-riok-3 from $H$. contortus [45] showed that Ce-riok-3 contains five exons of 54-580 bp in length and four introns of 43-612 bp, and that Hc-riok-3 contains 14 exons of 64-166 bp in length and 13 introns of 52-251 bp.

Analysis of the predicted promoter region of Ss-riok-3 Analysis of the 5'-flanking genomic region (1,600 bp in length) revealed that the gene immediately upstream of 


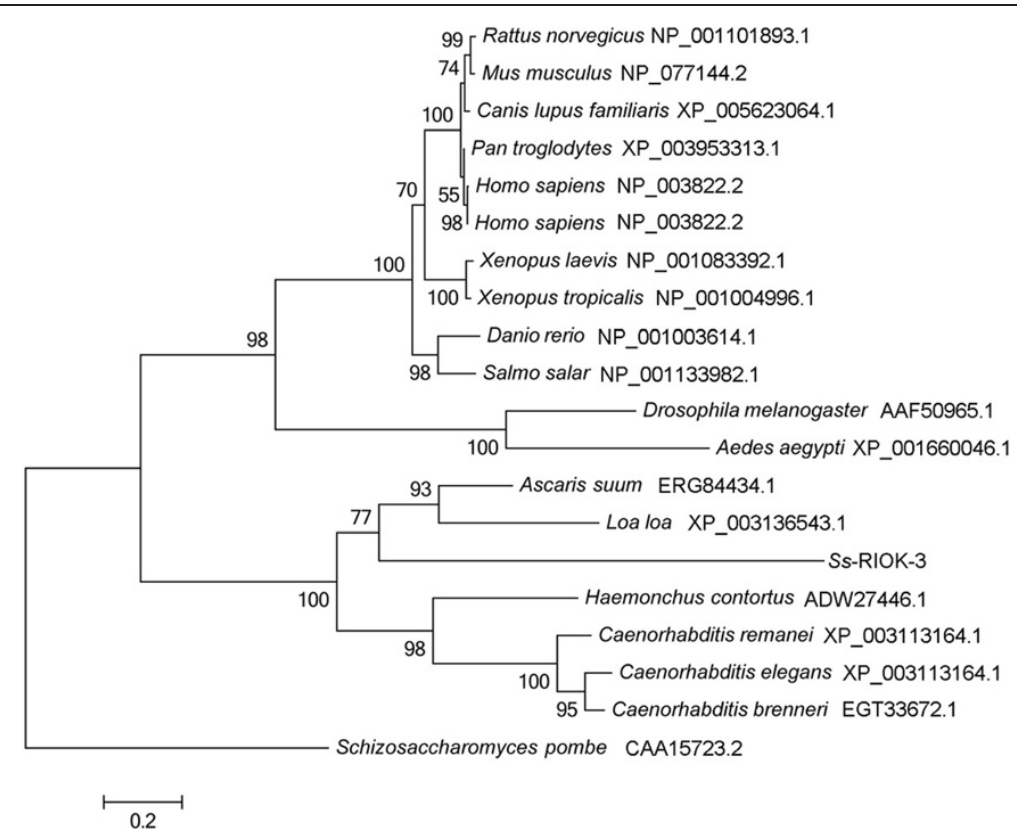

Figure 2 Phylogenetic relationship of Strongyloides stercoralis Ss-RIOK-3 with homologs from 18 selected species of eukaryote. These species include six nematode species, two insects, two fish, two amphibians and five mammals. The RIOK-3 from Schizosaccharomyces pombe (CAA15723.2) is used as an outgroup. GenBank accession numbers of sequences are listed beside the species name. Bootstrap values are displayed above or below the branches.

Ss-riok-3 is Ss-rep-1, the homolog of Ce-rep-1 (NM 001027757.3) encoding isoform a of C. elegans Rab escort protein (REP-1), which mediates Rab prenylation by binding with Rab proteins to regulate vesicular trafficking in cells [46-49]. The intergenic region between the termination codon of Ss-rep-1 and the start codon of Ss-riok-3 is $423 \mathrm{bp}$ in length, and contains the $114 \mathrm{bp}$ 3'-UTR of Ss-rep-1 and the 23 bp 5'-UTR of Ss-riok-3 separated by 286 bp of genomic DNA (Figure 4A). This region is $\mathrm{A}+\mathrm{T}$ rich with a content of $79 \%$. Ce-riok-3 is the downstream gene of operon CEOP3628 in C. elegans. Its upstream gene is $\mathrm{Ce}-Z K 632.4$, which encodes the homo$\log$ of human phosphomannose isomerase. The genomic region between Ce-riok-3 and Ce-ZK632.4 is 740 bp long, with an $\mathrm{A}+\mathrm{T}$ content of $68.4 \%$. The putative promoter region of Ss-riok-3, showed limited similarity to the 5'-flanking region of Ce-riok-3 (Figure 4B). The search for promoter elements identified four TATA, two GATA, one inverse GATA and one inverse CAAT boxes for Ss-riok-3. By contrast, the predicted promoter region of Ce-riok-3 contained one TATA, one GATA, two inverse GATA, three E-boxes and two inverse CAAT boxes. Three of the four TATA boxes in the promoter region of Ss-riok-3 are positioned in the 3'-UTR region of Ss-rep-1. The single TATA box in the 5 -flanking region of Ce-riok-3 is similarly situated in the 3'-UTR region of Ce-ZK632.4. The four

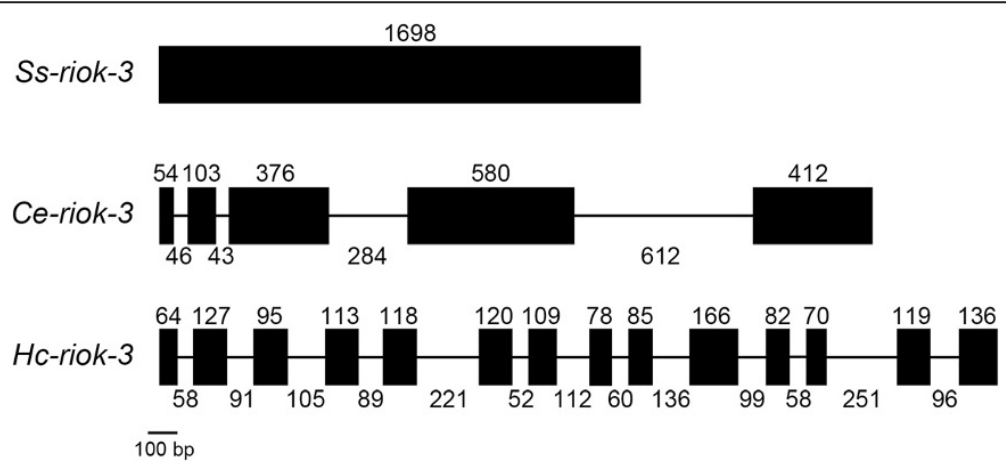

Figure 3 The gene structure of Strongyloides stercoralis Ss-riok-3 compared with its homologs from Caenorhabditis elegans and Haemonchus contortus. Black boxes indicate exons, with the numbers above indicating exon lengths. Introns are indicated by lines between the exons, with numbers indicating intron lengths. 


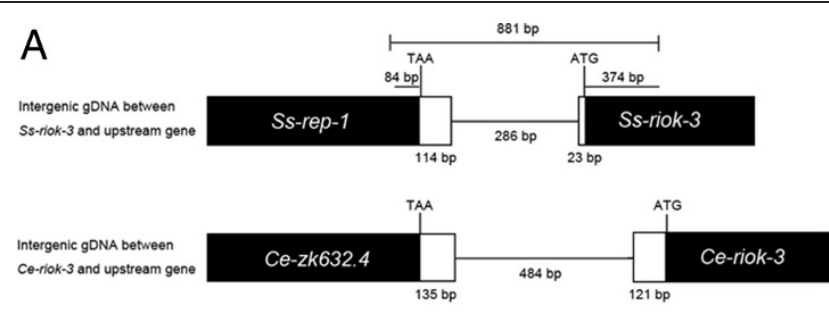

B

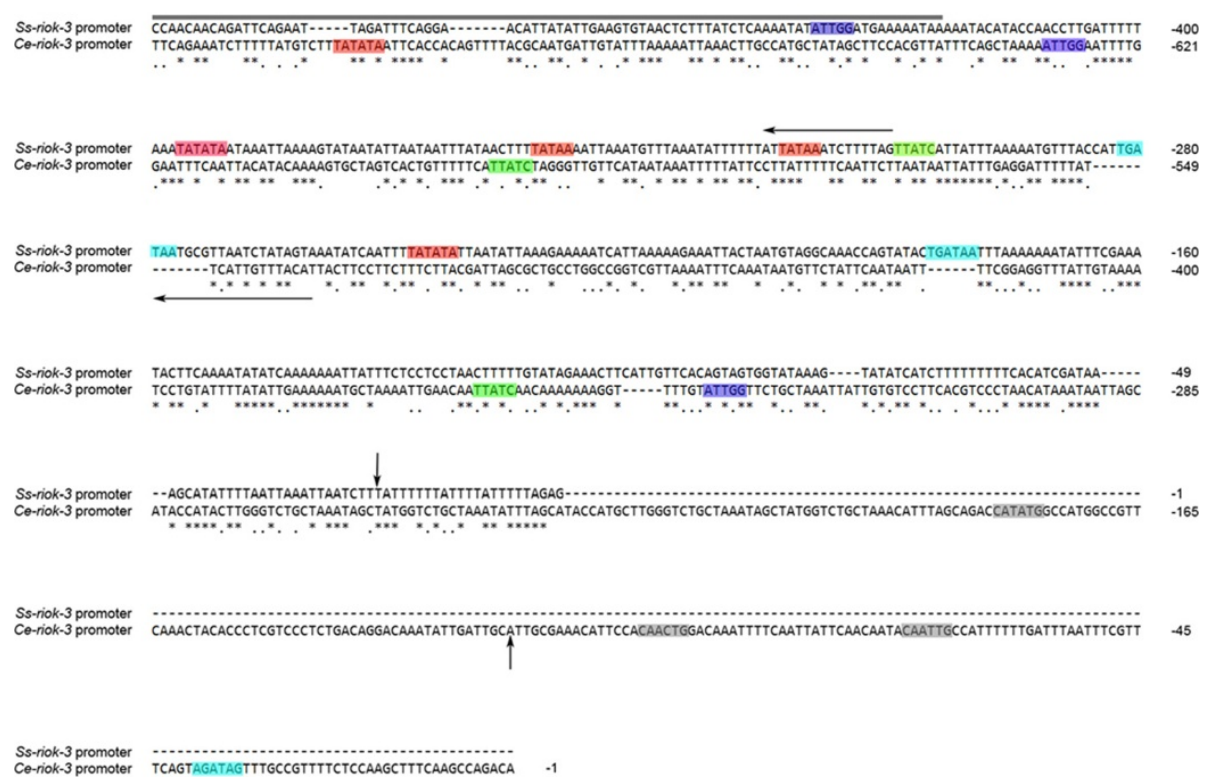

Figure 4 Diagram of upstream gene and intergenic regions of the genes Ss-riok-3 (Strongyloides stercoralis) and Ce-riok-3 (Caenorhabditis elegans), and alignment of promoter elements predicted from the upstream genomic DNA sequences of these two genes. (A) The upstream gene and intergenic regions. Black boxes indicate partial coding sequence, with gene name indicated; a white box indicates an untranslated region (UTR); a line indicates an intergenic region. Termination and initiation codons are marked on the coding strand, and UTRs and intergenic regions marked below white boxes and the lines, respectively. Brackets indicate genomic DNA inserted into the transformation constructs. (B) Alignment of the predicted promoters of Ss-riok-3 and Ce-riok-3. Genomic DNA sequences upstream of the initiation codon of Ss-riok-3 and Ce-riok-3 were aligned. Colored boxes represent the promoter elements: CAAT (CCAAT) or inverse CAAT (ATTGG) motif (blue), inverse GATA (TTATC) (green), GATA (WGATAR) (turquoise), E- (CANNTG) (grey) and TATA (red) boxes. The numbers represent the positions of the nucleotides upstream of the start codon. The thick black line above the Ss-riok-3 promoter indicates the 84 bp 3'-end of the coding sequence of Ss-rep-1. Left arrows above Ss-riok-3 and below Ce-riok-3 indicate the $3^{\prime}$-UTRs of the Ss-rep-1 and Ce-zk632.4. Vertical arrows indicate the transcription start site.

nucleotides preceding the start codon are AGAG in Ss-riok-3 and GACA in Ce-riok-3. Both of these sequences differ from the four nucleotides, AAAA, that commonly precede the start codons of protein-encoding genes in C. elegans [50].

\section{Transcriptional analysis of Ss-riok-3 in different developmental stages}

Ss-riok-3-specific transcripts were detected in all developmental stages of $S$. stercoralis assayed, with the highest abundance in P Females [please check whether P Female is used as a singular or plural noun throughout MS] and the lowest abundance in the PFL L1 (Figure 5). Notably, the abundances of Ss-riok-3 transcripts were higher in the parasitic stages of S. stercoralis, including P Female and L3+, than in the free-living stages, including PP L1, PP L3, FL Female, PFL L1 and iL3. Ss-riok-3 transcript abundance was significantly $(p<0.001)$ higher in $\mathrm{P}$ Females than in PP L1. A less marked, but significant $(p<0.05)$ increase in Ss-riok-3 transcript abundance was observed between L3+ and $\mathrm{P}$ Females. The abundance of Ss-riok-3 transcripts was minimal in PFL L1 and significantly lower than in parental FL Females $(p<0.05)$. There was a generally an increasing trend in Ss-riok-3 transcript abundance during development from PFL L1 to iL3 in the external environment, and in the further development within the host to the L3+ and then to the P Female. Although both parasitic and free-living females contained high levels of Ss-riok-3 mRNA, the abundance of these transcripts was significantly $(p<0.001)$ higher in P Females than in FL Females. 


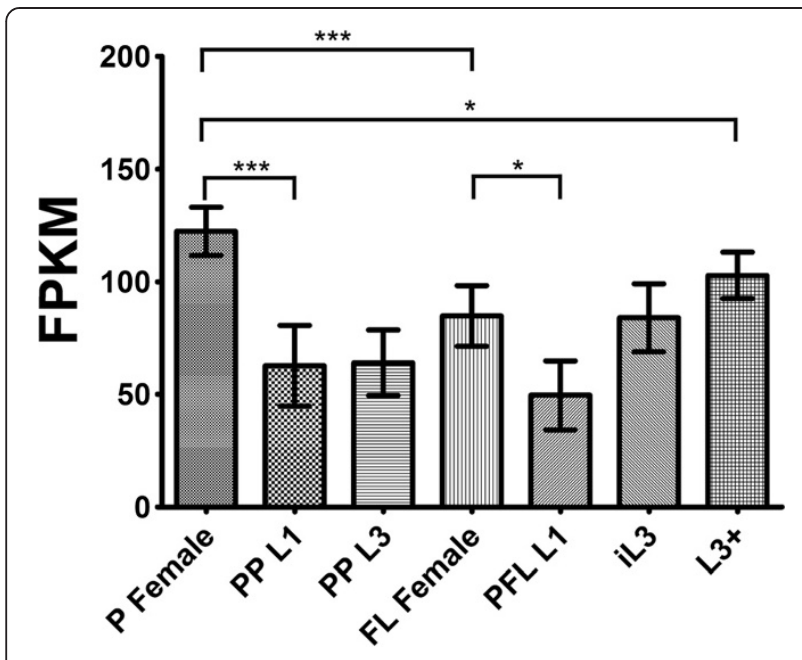

Figure 5 Transcriptional profiles for Strongyloides stercoralis Ss-riok-3. Transcript abundances were determined for the complete coding region of Ss-riok-3 for seven distinct developmental stages: parasitic females (P Female), post-parasitic first-stage larvae (PP L1), post-parasitic third-stage lanvae (PP L3), free-living females (FL Female), post free-living first-stage larvae (PFL L1), infective third-stage larvae (iL3), and in vivo activated third-stage larvae (L3+). Transcript abundance was calculated as fragments per kilobase of coding exon per million mapped reads (FPKM). Brackets with one star represent significant differences with a statistical probability of $p<0.05$. Brackets with three stars represent the significant differences with statistical probability of $p<0.001$. Error bars represent $95 \%$ confidential intervals.

\section{Anatomic expression pattern}

The anatomic expression pattern of Ss-riok-3 in vivo was inferred from those of $g f p$ expression under control of the 881 bp putative promoter in larval S. stercoralis transformed with pRP4 (Additional file 2); $48 \mathrm{~h}$ after transformation, the PFL L1 - L2s expressed GFP in the head neuron and intestine (Figure 6E,F). By contrast, GFP expression under the Ss-riok-3 promoter predominated in body muscle of iL3s transformed with pRP4 (Figure 6G,H). Worms transformed with pRP2, which includes a 683 bp putative Ss-riok-3 promoter, did not express GFP (data not shown). No fluorescence was observed in non-transgenic worms.

\section{Discussion}

RIOKs are atypical protein kinases, with the first representative (RIOK-1) discovered in yeast in 1997 [51]. All species contain at least two members of RIOK (i.e. RIOK-1 and RIOK-2), but multicellular, eukaryotic organisms studied to date also possess RIOK-3 [5]. In human cells and yeast, RIOK-1 and RIOK-2 play important roles in the process of ribosomal biology, including recycling of the trans-acting factors and/or rRNA cleavage [7-9,52]. Compared with RIOK-1 and RIOK-2, much less is known about RIOK-3. The function of RIOK-3 is different from those of RIOK-1 and RIOK-2 in human cells, with RIOK-3 controlling tumor cell invasiveness, suppressing the activity of NF- $\mathrm{kB}$ and supporting type I-interferon production $[13,14,53,54]$. Recently, human RIOK-3 was discovered in ribosomal 40S subunit particles [10].

Currently, nothing is known about the function of RIOK-3 in nematodes. We have begun to rectify this by investigating the structure, transcription patterns and anatomic expression of Ss-riok-3, the RIOK-3-encoding gene from $S$. stercoralis. We identified only one transcript of Ss-riok-3; however, in C. elegans, there are two transcript variants (isoforms) of Ce-riok-3, with the same coding sequence but with 5'-UTRs of differing lengths (http://www. wormbase.org/). The human genome also encodes an additional riok-3 transcript variant, but the relevant locus is predicted to be a pseudo-gene [4]. Consistent with our findings for S. stercoralis, riok-3 genes of other parasitic nematodes, including A. suum, Dirofilaria immitis and $H$. contortus, appear to produce only one transcript.

All four reported members from the RIO protein kinase family (i.e. RIOK-1, RIOK-2, RIOK-3 and RIOK-B) contain the conserved RIO domain, including an ATP binding motif, a flexible loop, a hinge, an active site and a metalbinding motif [5]. The RIO domain is similarly conserved in Ss-RIOK-3. Like the RIOK-1 s and RIOK-2 s, RIOK-3 s also lacks the substrate-binding motif present in ePKs, but has an inserted flexible loop [3,5]. It is interesting that the predicted peptide sequence of the ATP-binding motif of Ss-RIOK-3 has two aa substitutions compared with those of the other species studied herein. For example, the sequence is ASGKES in S. stercoralis and S. ratti, ATGKES in the other nematodes and STGKES in the non-nematode species selected. Analyses of RIOK-1 and RIOK-2 in a complex with ATP $[6,55]$ reveal that the putative ATP binding motif, along with the beta strand-three, actually participate in binding ATP and that the Lys (K) located in the beta strand-three is required for this interaction. Site mutation changing the Lys $(\mathrm{K})$ in the beta strand-three to Ala (A) in the ATP binding motifs of RIOK-2 and RIOK-3 in yeast and human cells ablate the ATP binding activity and affect the kinase functions of these enzymes [54,56]. Although the Lys (K) from the ATP binding loop does not directly interact with ATP, it is essential for RIOK-2 to bind with pre-40S subunit to participate in ribosomal biogenesis [56]. Whether the aa substitutions in the ATPbinding motif of Ss-RIOK-3 influence its affinity for ATP or AMP is unknown and warrants future investigation.

An alignment of predicted aa sequences (Figure 1) also revealed that RIOK-3 s from selected species, including Ss-RIOK-3, contain a N-terminal region that is much larger than the $\mathrm{N}$-terminal regions of RIOK-1 $\mathrm{s}$ and RIOK-2 s. This finding is consistent with a comparative analysis of the predicted structures for RIOKs from C. elegans and parasitic nematodes for which extensive 


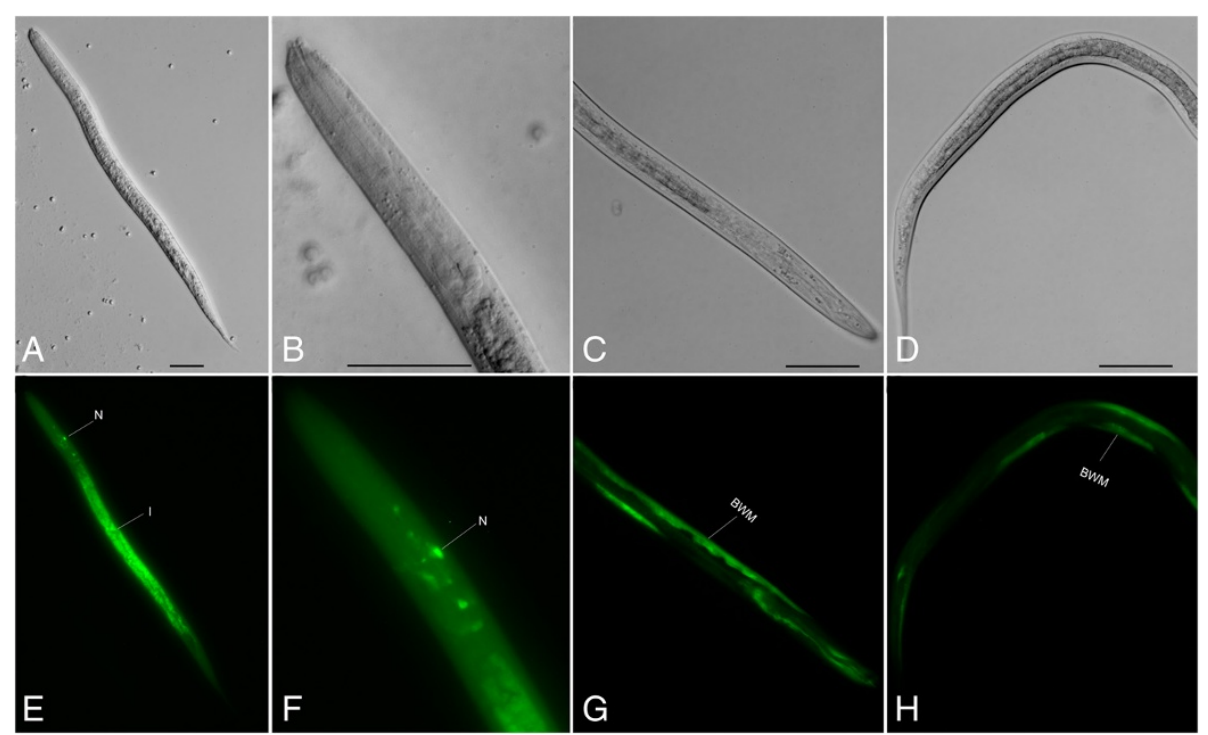

Figure 6 The anatomical expression pattern of Ss-riok-3 in the post-free-living first and second stage larvae and infective third stage larvae of Strongyloides stercoralis. DIC (A,B) and fluorescence $(\mathbf{E}, \mathbf{F})$ images of transgenic S. stercoralis post-free-living L1-L2 stage larvae expressing Ss-riok3p:::gfp::Ss-era-1 t. (A,E,); GFP expression in the intestine (i) and head neuron (N). DIC $(\mathbf{C}, \mathbf{D})$ and fluorescence $(\mathrm{G}, \mathrm{H})$ images of transgenic $S$. stercoralis infective third stage larvae expressing Ss-riok-3p::gfp::Ss-era-1 t. (G,H) GFP expression in the body wall muscle (BWM; white arrows). Scale bars = 50 $\mu m$.

genomic and transcriptomic data sets are available [57]. The precise function of this N-terminal region of RIOK-3 s is unknown; however, findings for RIOK-3 in human cells support that the N-terminal region of this RIOK-3 is involved in the binding of polyubiquitin and the suppression of TNF $\alpha$-mediated NF-kB activity [14,53]. In addition, bioinformatic analysis predicts that the $\mathrm{N}$-terminal region of $\mathrm{Ce}$-RIOK-3 is involved in transmembrane transport [57]. In the present study, the Strongyloides RIOK-3 s (Ss-RIOK-3 and $\mathrm{Sr}$-RIOK-3) contained a larger N-terminus than RIOK$3 \mathrm{~s}$ from other selected species; this largely reflects the low sequence identity between Strongyloides RIOK-3 and its homologs. This difference suggests that the $\mathrm{N}$-terminus of Ss-RIOK-3 might have a unique function.

The analysis of the S. stercoralis transcriptome reveals that the transcription of Ss-riok-3 is high in the parasitic life stages of this worm, with the highest level in $\mathrm{P}$ Females. It also shows that, with the exception of iL3, transcripts of Ss-riok-3 are more abundant in FL Females than in post parasitic and post free-living larvae. The abundance of Ss-riok-3 transcripts in female worms suggests that $S s-r i o k-3$ plays a functional role in reproduction. Due to the absence of transcripts from FL Males, we could not compare transcript abundance between FL Females and FL Males. However, as S. stercoralis is parthenogenetic, there is no male adult within the host. Nonetheless, the peak transcript abundance in P Females still suggests a key function for $S s$-RIOK-3 in this developmental stage. In other parasitic nematodes (A. suum, B. malayi and $H$. contortus) riok-3 is transcribed at high levels in eggs but does not show significant differences between female and male adults in these three parasites [57]. This information is consistent with trends of riok-3 transcription in embryos of C. elegans and parasitic nematodes, supporting the proposal of constitutive expression of this gene during embryogenesis $[57,58]$.

Notably, Ss-riok-3 transcription is also enriched in L3+, which have invaded the host and resumed development to the P Female stage. The abundance of Ss-riok-3 transcript in the parasitic stages of $S$. stercoralis might indicate that Ss-RIOK-3 participates in sexual maturation of L3s developing to P Females. In C. elegans, analysis of gene expression cluster during sexual differentiation revealed that $\mathrm{Ce}$-riok-3 is enriched in mature hermaphrodites [59]. This trend is echoed by the enrichment of Ss-riok-3 transcripts in the P Females and FL Females of S. stercoralis, suggesting its possible roles in female reproductive biology of this nematode. The analyses of transcript abundance did not show transcriptional difference between FL Females and iL3, however, the promoter activity also shifts from intestine in PFL L1 to body wall muscle in iL3, which suggest that $S s$-RIOK-3 could be involved in maintaining the activity of body wall muscle of iL3 to support hostfinding and infection.

Ce-riok-3 is present in an operon (CEOP3628) [60]. A similar genomic context is not supported for Ss-riok-3, as the donor SL1 and SL2 snoRNA is absent from the 5' end of Ss-riok-3 cDNA, indicating no association with an operon; the gene immediately upstream of Ss-riok-3 (Ss-rep-1) is not found in the 5'-flanking region of Ce-riok-3. The intergenic region between the stop codon of Ss-rep-1 and the start codon of Ss-riok-3 is $423 \mathrm{bp}$. In the 
initial gene localization analysis, the 309 bp genomic DNA, comprising 23 bp of 5'-UTR of Ss-riok-3 and the 286 bp of intergenic region between the start codon of Ss-riok-3 and the end of 3'-UTR of Ss-rep-1 (Additional file 2), was predicted to be the promoter region of Ss-riok-3 and was thus cloned into the reporter gene plasmid to make a transformation construct pRP2 (Additional file 2). However, this region did not drive GFP expression in PFL L1-L2s (data not shown). Only the transformation construct (pRP4) comprising 423 bp genomic DNA region, including the $23 \mathrm{bp}$ of 5'UTR of Ss-riok-3, the 286 bp of intergenic genomic DNA and the 114 bp of 3'-UTR of Ss-rep-1, drove strong GFP expression in the intestine and head neuron of PFL L1s and L2s of S. stercoralis. The analysis of the potential promoter regions of $S s$-riok-3 revealed that three of the four TATA boxes in the 5'-flanking region of Ss-riok-3 are actually located in the 3'-UTR of Ss-rep-1 which is immediately upstream of $S s$-riok-3. Failure of the 683 bp promoter element in pRP2, which lacks these three TATA boxes, to drive $g f p$ expression and the contrasting, robust reporter expression under control of the 881 bp promoter element in pRP4, which includes them, demonstrates that, despite their location within the regulatory sequences of another gene, the three TATA boxes in the 3'-UTR of Ss-rep-1 are essential for initiating transcription of Ss-riok-3 in vivo. The TATA box is a common promoter element, which is recognized by RNA polymerase II during transcription initiation in most protein-coding genes [61,62]. Also present in the putative Ss-riok-3 promoter are four GATA and two inverse GATA boxes. The GATA transcription factor (TF) family consists of GATA 1 to 6 that contain zinc finger motif capable of binding to target DNA [63]. GATA transcription factors regulate gene expression and play important roles in eukaryotic development [64-68]. In C. elegans, GATA TFs regulate gut-specific gene transcription, and ELT-2 TF predominantly controls the development of the intestine $[69,70]$. The present results showed that the sequences of GATA boxes (TGATAA) in the predicted promoter region of Ss-riok-3 are consistent with ELT-2 binding sequence in C. elegans, which indicate GATA TFs regulate Ss-riok-3 transcription and expression in the intestine of PFL L1s.

The activity of the $S s$-riok-3 promoter in the intestine of PFL L1-L2s is consistent with results of a high-throughput in vivo-analysis of gene expression in C. elegans, revealing that $\mathrm{Ce}$-riok-3 is expressed in the intestine of larvae and adults [71,72]. In $C$. elegans, the intestine is a relatively large and important organ whose functions include not only digestion of food and absorption of nutrients, but also synthesis and storage of macromolecules, initiation of innate immune response to pathogens as well as the production of egg yolk protein [73-76]. In C. elegans, the intestine develops from a single cell lineage, beginning with progenitor cell E. During this development, GATA TFs regulate and activate intestine-specific gene expression which supports intestinal differentiation and maintenance [75,77]. Distinctive localization of Ce-riok-3 to larval and adult intestine and its enrichment in hermaphrodites [59] could indicate that $\mathrm{Ce}$-RIOK-3 supports intestinal development and function, and suggests that RIOK-3 plays a role in the reproductive biology of $C$. elegans. Similarly, the abundance of Ss-riok-3 transcripts in P Females and FL Females of $S$. stercoralis as well as the intestinal localization of Ss-riok-3 promoter activity suggest that $\mathrm{Ss}$ RIOK-3 supports intestinal function during development from larvae to adults, and possibly reproductive functions in adult females of this parasitic nematode.

In addition to the intestine of S. stercoralis, the head neuron of PFL L1 - L2s also had GFP expression that is unique to $S$. stercoralis compared with expression pattern for Ce-riok-3 in C. elegans, indicating a functional difference between $S s$-RIOK-3 and Ce-RIOK-3, and could suggest central and distinctive roles for RIOK-3 in the S. stercoralis, which warrant further investigation. Also, the shift of Ss-riok-3 promoter activity from intestine in PFL L1-L2s to body wall muscle in iL3s, which is also found in the promoter activity of Ss-riok-1 from neurons in PFL L1 to body wall muscle in iL3 [42], suggests a remolding of tissues in iL3 to prepare the parasite for infecting the host animal [2].

\section{Conclusions}

In conclusion, we have identified the RIOK-3 encoding gene Ss-riok-3 in S. stercoralis. Ss-RIOK-3 is predicted to contain conserved RIO domain with two aa substitutions in the ATP-binding motif compared with RIOK-3 s from other nematodes, and from other selected species of invertebrates and vertebrates. Ss-riok-3 transcripts are most abundant in the parasitic stages of $S$. stercoralis, and the $S$ sriok-3 promoter is active in the intestine and some cephalic neurons of PF L1-L2s, suggesting that Ss-riok-3 supports the development of the intestine of larvae and could be involved in the reproductive biology of female adults. The shift of Ss-riok-3 promoter activity during the development of S. stercoralis from PFL L1 to iL3 suggests a potential role of Ss-riok-3 in morphogenesis of iL3. The finding that the TATA boxes located in the 3'-UTR of Ss-rep-1, the gene immediately upstream of Ss-riok-3, are essential regulatory elements to initiate the transcription of Ss-riok-3 also underscores the functional overlap of regulatory sequences in genes that are closely linked in the $S$. stercoralis genome. Whether Ss-RIOK-3 participates in the reproductive biology in female adults still needs further investigation.

\section{Additional files}

Additional file 1: Codes and DNA sequences of oligonucleotide primers used in the present study. These primers were employed for the isolation of $3^{\prime}$ cDNA of Ss-rep-1, cDNAs and predicted promoter 
regions of Ss-riok-3 using PCR-based approaches and for the construction of plasmids for transgenesis.

Additional file 2: Diagram of Ss-riok-3 transcriptional reporter construct PRP2 and pRP4 used to transform. Strongyloides stercoralis. The promoter structure of Ss-riok-3 is shown. (A) Black box represents a coding region of the gene. White box represents the un-translated region. Line represents intergenic region. The lengths of intergenic region, untranslated region, regions that were cloned into the pAJ 02 vector are marked above or below each corresponding region indicated with brackets. (B) The Hindlll and Smal restrict sites along with the start codon of $g f p$ were marked. The length of sequence with an artificial intron between the Smal restrict site and gfp start codon is indicated. The $683 \mathrm{bp}$ and 881 bp regions (marked below and above the promoter structure, respectively) between Ss-rep-1 and Ss-riok-3 were separately inserted into the vector pAJ02 [41], creating plasmids pRP2 and pRP4, respectively. Length of gfp with artificial introns and Ss-era-1 $3^{\prime}$-untranslated region (UTR) in the constructs are indicated.

\section{Competing interests}

The authors declare that they have no competing interests.

\section{Authors' contributions}

Conceived and designed the experiment: MH. Performed the experiments: WY and YYL. Analyzed the data: WY, JDS, JBL and MH. Contributed reagents/ materials/analysis tools: WY, YYL, JDS, JBL, MH, RBG, WQL, RF and JLZ. Contributed to the writing of the manuscript: $\mathrm{WY}, \mathrm{MH}, \mathrm{JBL}$ and RBG. All authors read and approved the final version of the MS.

\section{Acknowledgements}

Sincere thanks to Hongguang Shao and Xinshe Li for assistance with gonad injection in S. stercoralis. This study was supported by the Special Fund for Agro-scientific Research in the Public Interest (Grant No. 201303037) and the Fundamental Research Funds for the Central Universities (Program no. 2011PY118) to MH, and by grants from the National Institutes of Health $(\mathrm{NIH})$, USA (Al-050688, Al-082548 and Al-105856) to JBL. Funds from the National Health and Medical Research Council (NHMRC) of Australia and the Australian Research Council (ARC) are gratefully acknowledged (RBG); this study was also supported by a Victorian Life Sciences Computation Initiative (VLSCI) grant number VRO007 on its Peak Computing Facility at the University of Melbourne, an initiative of the Victorian Government (RBG). Other support from the Australian Academy of Science and the Alexander von Humboldt Foundation is gratefully acknowledged (RBG).

\section{Author details}

${ }^{1}$ State Key Laboratory of Agricultural Microbiology, Key Laboratory of Development of Veterinary Diagnostic Products, Ministry of Agriculture, College of Veterinary Medicine, Huazhong Agricultural University, 1 Shizishan Street, Wuhan 430070, China. ${ }^{2}$ Department of Pathobiology, School of Veterinary Medicine, University of Pennsylvania, 3800 Spruce Street, Philadelphia, PA 19104, USA. ${ }^{3}$ Department of Biology, Hollins University, Roanoke, VI 24020, USA. ${ }^{4}$ Faculty of Veterinary and Agricultural Sciences, The University of Melbourne, Corner of Flemington Road and Park Drive, Parkville, VI 3010, Australia.

Received: 28 August 2014 Accepted: 23 November 2014 Published online: 05 December 2014

\section{References}

1. Croker C, Reporter R, Redelings M, Mascola L: Strongyloidiasis-related deaths in the United States, 1991-2006. Am J Trop Med Hyg 2010, 83(2):422-426.

2. Schad G: Morphology and life history of Strongyloides stercoralis. In Strongyloidiasis: a Major Roundworm Infection of Man. Philadelphia: Taylor \& Francis; 1989:85-104.

3. Hanks SK, Quinn AM, Hunter T: The protein kinase family: conserved features and deduced phylogeny of the catalytic domains. Science 1988 241(4861):42-52

4. Manning G, Whyte DB, Martinez R, Hunter T, Sudarsanam S: The protein kinase complement of the human genome. Science 2002, 298(5600):1912-1934.
5. LaRonde-LeBlanc N, Wlodawer A: A family portrait of the RIO kinases. J Biol Chem 2005, 280(45):37297-37300

6. LaRonde-LeBlanc N, Guszczynski T, Copeland T, Wlodawer A: Structure and activity of the atypical serine kinase Rio1. FEBS J 2005, 272(14):3698-3713.

7. Vanrobays E, Gleizes PE, Bousquet-Antonelli C, Noaillac-Depeyre J, Caizergues-Ferrer M, Gelugne JP: Processing of 20S pre-rRNA to $18 \mathrm{~S}$ ribosomal RNA in yeast requires Rrp10p, an essential non-ribosomal cytoplasmic protein. EMBO J 2001, 20(15):4204-4213.

8. Geerlings TH, Faber AW, Bister MD, Vos JC, Raue HA: Rio2p, an evolutionarily conserved, low abundant protein kinase essential for processing of $20 \mathrm{~S}$ Pre-rRNA in Saccharomyces cerevisiae. J Biol Chem 2003, 278(25):22537-22545.

9. Widmann B, Wandrey F, Badertscher L, Wyler E, Pfannstiel J, Zemp I, Kutay U: The kinase activity of human Rio1 is required for final steps of cytoplasmic maturation of 40S subunits. Mol Biol Cell 2012, 23(1):22-35.

10. Baumas $K$, Soudet J, Caizergues-Ferrer M, Faubladier M, Henry Y, Mougin A: Human RioK3 is a novel component of cytoplasmic pre-40S pre-ribosomal particles. RNA Biol 2012, 9(2):162-174.

11. Roesch A, Vogt T, Stolz W, Dugas M, Landthaler M, Becker B: Discrimination between gene expression patterns in the invasive margin and the tumour core of malignant melanomas. Melanoma Res 2003, 13(5):503-509.

12. Giri U, Ashorn CL, Ramdas L, Stivers DN, Coombes K, El-Naggar AK, Ang KK, Story MD: Molecular signatures associated with clinical outcome in patients with high-risk head-and-neck squamous cell carcinoma treated by surgery and radiation. Int J Radiat Oncol Biol Phys 2006, 64(3):670-677.

13. Kimmelman AC, Hezel AF, Aguirre AJ, Zheng H, Paik JH, Ying H, Chu GC, Zhang JX, Sahin E, Yeo G, Ponugoti A, Nabioullin R, Deroo S, Yang S, Wang X, McGrath JP, Protopopova M, Ivanova E, Zhang J, Feng B, Tsao MS, Redston M, Protopopov A, Xiao Y, Futreal PA, Hahn WC, Klimstra DS, Chin L, DePinho RA: Genomic alterations link Rho family of GTPases to the highly invasive phenotype of pancreas cancer. Proc Natl Acad Sci U S A 2008, 105(49):19372-19377.

14. Shan J, Wang P, Zhou J, Wu D, Shi H, Huo K: RIOK3 interacts with caspase- 10 and negatively regulates the NF-kappaB signaling pathway. Mol Cell Biochem 2009, 332(1-2):113-120.

15. Stephens P, Edkins S, Davies H, Greenman C, Cox C, Hunter C, Bignell G, Teague J, Smith R, Stevens C, O'Meara S, Parker A, Tarpey P, Avis T, Barthorpe A, Brackenbury L, Buck G, Butler A, Clements J, Cole J, Dicks E, Edwards K, Forbes S, Gorton M, Gray K, Halliday K, Harrison R, Hills K, Hinton J, Jones $\mathrm{D}$, et al: A screen of the complete protein kinase gene family identifies diverse patterns of somatic mutations in human breast cancer. Nat Genet 2005, 37(6):590-592.

16. Gonczy P, Echeverri C, Oegema K, Coulson A, Jones SJ, Copley RR, Duperon J, Oegema J, Brehm M, Cassin E, Hannak E, Kirkham M, Pichler S, Flohrs K, Goessen A, Leidel S, Alleaume AM, Martin C, Ozlu N, Bork P, Hyman AA: Functional genomic analysis of cell division in C. elegans using RNAi of genes on chromosome III. Nature 2000, 408(6810):331-336.

17. Rual JF, Ceron J, Koreth J, Hao T, Nicot AS, Hirozane-Kishikawa T, Vandenhaute J, Orkin SH, Hill DE, van den Heuvel S, Vidal M: Toward improving Caenorhabditis elegans phenome mapping with an ORFeome-based RNAi library. Genome Res 2004, 14(10B):2162-2168.

18. Sonnichsen B, Koski LB, Walsh A, Marschall P, Neumann B, Brehm M, Alleaume AM, Artelt J, Bettencourt P, Cassin E, Hewitson M, Holz C, Khan M, Lazik S, Martin C, Nitzsche B, Ruer M, Stamford J, Winzi M, Heinkel R, Roder M, Finell J, Hantsch H, Jones SJ, Jones M, Piano F, Gunsalus KC, Oegema K, Gonczy P, Coulson A, et al: Full-genome RNAi profiling of early embryogenesis in Caenorhabditis elegans. Nature 2005, 434(7032):462-469.

19. Geldhof P, Visser A, Clark D, Saunders G, Britton C, Gilleard J, Berriman M, Knox D: RNA interference in parasitic helminths: current situation, potential pitfalls and future prospects. Parasitology 2007, 134(Pt 5):609-619.

20. Castelletto ML, Massey HC Jr, Lok JB: Morphogenesis of Strongyloides stercoralis infective larvae requires the DAF-16 ortholog FKTF-1. PLoS Pathog 2009, 5(4):e1000370.

21. Li X, Massey HC Jr, Nolan TJ, Schad GA, Kraus K, Sundaram M, Lok JB: Successful transgenesis of the parasitic nematode Strongyloides stercoralis requires endogenous non-coding control elements. Int J Parasitol 2006, 36(6):671-679.

22. Shao H, Li X, Nolan TJ, Massey HC Jr, Pearce EJ, Lok JB: Transposonmediated chromosomal integration of transgenes in the parasitic nematode Strongyloides ratti and establishment of stable transgenic lines. PLoS Pathog 2012, 8(8):e1002871. 
23. Lok JB, Massey HC Jr: Transgene expression in Strongyloides stercoralis following gonadal microinjection of DNA constructs. Mol Biochem Parasitol 2002, 119(2):279-284.

24. Lok JB: Strongyloides stercoralis: a model for translational research on parasitic nematode biology. In WormBook. 2007:1-18.

25. Hawdon J, Schad G: Long term storage of hookworm infective larvae in buffered saline solution maintains larval responsiveness to host signals. J Helm Soc Wash 1991, 58:140-142.

26. Bowman DD, Lynn RC: Georgi's Parasitology for Veterinarians. WB Saunders Company. Saint Louis, Missouri, U.S.A: W B Saunders Co; 1995

27. Gasser RB, Chilton NB, Hoste H, Beveridge I: Rapid sequencing of rDNA from single worms and eggs of parasitic helminths. Nucleic Acids Res 1993, 21(10):2525-2526.

28. Altschul SF, Madden TL, Schaffer AA, Zhang J, Zhang Z, Miller W, Lipman DJ: Gapped BLAST and PSI-BLAST: a new generation of protein database search programs. Nucleic Acids Res 1997, 25(17):3389-3402.

29. Bairoch A: The PROSITE dictionary of sites and patterns in proteins, its current status. Nucleic Acids Res 1993, 21(13):3097-3103.

30. Bateman A, Birney E, Durbin R, Eddy SR, Howe KL, Sonnhammer EL: The Pfam protein families database. Nucleic Acids Res 2000, 28(1):263-266.

31. Katoh K, Standley DM: MAFFT multiple sequence alignment software version 7: improvements in performance and usability. Mol Biol Evol 2013, 30(4):772-780.

32. Deyneko IV, Kel AE, Kel-Margoulis OV, Deineko EV, Wingender E, Weiss S: MatrixCatch-a novel tool for the recognition of composite regulatory elements in promoters. BMC Bioinformatics 2013, 14:241.

33. Tamura K, Peterson D, Peterson N, Stecher G, Nei M, Kumar S: MEGA5: molecular evolutionary genetics analysis using maximum likelihood, evolutionary distance, and maximum parsimony methods. Mol Biol Evol 2011, 28(10):2731-2739.

34. Stoltzfus JD, Massey HC Jr, Nolan TJ, Griffith SD, Lok JB: Strongyloides stercoralis age-1: a potential regulator of infective larval development in a parasitic nematode. PLoS One 2012, 7(6):e38587.

35. Stoltzfus JD, Minot S, Berriman M, Nolan TJ, Lok JB: RNAseq analysis of the parasitic nematode Strongyloides stercoralis reveals divergent regulation of canonical dauer pathways. PLoS Negl Trop Dis 2012, 6(10):e1854.

36. Nolan TJ, Megyeri Z, Bhopale VM, Schad GA: Strongyloides stercoralis: the first rodent model for uncomplicated and hyperinfective strongyloidiasis, the Mongolian gerbil (Meriones unguiculatus). J Infect Dis 1993, 168(6):1479-1484

37. Schad GA, Hellman ME, Muncey DW: Strongyloides stercoralis: hyperinfection in immunosuppressed dogs. Exp Parasitol 1984, 57(3):287-296.

38. Mortazavi A, Williams BA, McCue K, Schaeffer L, Wold B: Mapping and quantifying mammalian transcriptomes by RNA-Seq. Nat Methods 2008, 5(7):621-628.

39. Trapnell C, Roberts A, Goff L, Pertea G, Kim D, Kelley DR, Pimentel H, Salzberg SL, Rinn JL, Pachter L: Differential gene and transcript expression analysis of RNA-seq experiments with TopHat and Cufflinks. Nat Protoc 2012, 7(3):562-578

40. Trapnell C, Hendrickson DG, Sauvageau M, Goff L, Rinn JL, Pachter L: Differential analysis of gene regulation at transcript resolution with RNA-seq. Nat Biotechnol 2013, 31(1):46-53.

41. Junio AB, Li X, Massey HC Jr, Nolan TJ, Todd Lamitina S, Sundaram MV Lok JB: Strongyloides stercoralis: cell- and tissue-specific transgene expression and co-transformation with vector constructs incorporating a common multifunctional 3' UTR. Exp Parasitol 2008, 118(2):253-265.

42. Yuan W, Lok JB, Stoltzfus JD, Gasser RB, Fang F, Lei WQ, Fang R, Zhou YQ, Zhao JL, Hu M: Toward understanding the functional role of Ss-riok-1, a RIO protein kinase-encoding gene of Strongyloides stercoralis. PLoS Negl Trop Dis 2014, 8(8):e3062

43. Angermayr M, Roidl A, Bandlow W: Yeast Rio1p is the founding member of a novel subfamily of protein serine kinases involved in the control of cell cycle progression. Mol Microbiol 2002, 44(2):309-324.

44. Blaxter ML, De Ley P, Garey JR, Liu LX, Scheldeman P, Vierstraete A, Vanfleteren JR, Mackey LY, Dorris M, Frisse LM, Vida JT, Thomas WK: A molecular evolutionary framework for the phylum Nematoda. Nature 1998, 392(6671):71-75.

45. Campbell BE, Boag PR, Hofmann A, Cantacessi C, Wang CK, Taylor P, Hu M, Sindhu ZU, Loukas A, Sternberg PW, Gasser RB: Atypical (RIO) protein kinases from Haemonchus contortus - promise as new targets for nematocidal drugs. Biotechnol Adv 2011, 29(3):338-350.

46. Andres DA, Seabra MC, Brown MS, Armstrong SA, Smeland TE, Cremers FP, Goldstein JL: cDNA cloning of component A of Rab geranylgeranyl transferase and demonstration of its role as a Rab escort protein. Cell 1993, 73(6):1091-1099.

47. Nonet ML, Staunton JE, Kilgard MP, Fergestad T, Hartwieg E, Horvitz HR, Jorgensen EM, Meyer BJ: Caenorhabditis elegans rab-3 mutant synapses exhibit impaired function and are partially depleted of vesicles. J Neurosci 1997, 17(21):8061-8073.

48. Novick P, Zerial M: The diversity of Rab proteins in vesicle transport. Curr Opin Cell Biol 1997, 9(4):496-504.

49. Mahoney TR, Liu Q, Itoh T, Luo S, Hadwiger G, Vincent R, Wang ZW, Fukuda M, Nonet ML: Regulation of synaptic transmission by RAB-3 and RAB-27 in Caenorhabditis elegans. Mol Biol Cell 2006, 17(6):2617-2625.

50. Blumenthal T, Steward K: RNA Processing and Gene Structure. In C elegans II. 2nd edition. Edited by Riddle DL, Blumenthal T, Meyer BJ, Priess JR. Cold Spring Harbor (NY): 1997

51. Angermayr M, Bandlow W: The type of basal promoter determines the regulated or constitutive mode of transcription in the common control region of the yeast gene pair GCY1/RIO1. J Biol Chem 1997, 272(50):31630-31635.

52. Vanrobays E, Gelugne JP, Gleizes PE, Caizergues-Ferrer M: Late cytoplasmic maturation of the small ribosomal subunit requires RIO proteins in Saccharomyces cerevisiae. Mol Cell Biol 2003, 23(6):2083-2095.

53. Fenner BJ, Scannell M, Prehn JH: Identification of polyubiquitin binding proteins involved in NF-kappaB signaling using protein arrays. Biochim Biophys Acta 2009, 1794(7):1010-1016.

54. Feng J, De Jesus PD, Su V, Han S, Gong D, Wu NC, Tian Y, Li X, Wu T-T, Chanda SK: RIOK3 is an adaptor protein required for IRF3-mediated antiviral type I interferon production. J Virol 2014, JVl:00614-00643.

55. LaRonde-LeBlanc N, Wlodawer A: Crystal structure of A. fulgidus Rio2 defines a new family of serine protein kinases. Structure 2004, 12(9):1585-1594.

56. Ferreira-Cerca S, Sagar V, Schafer T, Diop M, Wesseling AM, Lu H, Chai E, Hurt E, LaRonde-LeBlanc N: ATPase-dependent role of the atypical kinase Rio2 on the evolving pre-40S ribosomal subunit. Nat Struct Mol Biol 2012, 19(12):1316-1323.

57. Breugelmans B, Jex AR, Korhonen PK, Mangiola S, Young ND, Sternberg PW, Boag PR, Hofmann A, Gasser RB: Bioinformatic exploration of RIO protein kinases of parasitic and free-living nematodes. Int J Parasitol 2014, 44(11):827-836.

58. Levin M, Hashimshony $T$, Wagner F, Yanai I: Developmental milestones punctuate gene expression in the Caenorhabditis embryo. Dev Cell 2012 22(5):1101-1108.

59. Reinke V, Gil IS, Ward S, Kazmer K: Genome-wide germline-enriched and sex-biased expression profiles in Caenorhabditis elegans. Development 2004, 131(2):311-323.

60. Blumenthal T, Evans D, Link CD, Guffanti A, Lawson D, Thierry-Mieg J, Thierry-Mieg D, Chiu WL, Duke K, Kiraly M, Kim SK: A global analysis of Caenorhabditis elegans operons. Nature 2002, 417(6891):851-854.

61. Breathnach R, Chambon P: Organization and expression of eucaryotic split genes coding for proteins. Annu Rev Biochem 1981, 50:349-383.

62. Corden J, Wasylyk B, Buchwalder A, Sassone-Corsi P, Kedinger C, Chambon P: Promoter sequences of eukaryotic protein-coding genes. Science 1980 209(4463):1406-1414.

63. Patient RK, McGhee JD: The GATA family (vertebrates and invertebrates). Curr Opin Genet Dev 2002, 12(4):416-422.

64. Abel T, Michelson AM, Maniatis T: A Drosophila GATA family member that binds to Adh regulatory sequences is expressed in the developing fat body. Development 1993, 119(3):623-633.

65. Arceci RJ, King AA, Simon MC, Orkin SH, Wilson DB: Mouse GATA-4: a retinoic acid-inducible GATA-binding transcription factor expressed in endodermally derived tissues and heart. Mol Cell Biol 1993, 13(4):2235-2246.

66. Kelley C, Blumberg H, Zon LI, Evans T: GATA-4 is a novel transcription factor expressed in endocardium of the developing heart. Development 1993, 118(3):817-827.

67. Laverriere AC, MacNeill C, Mueller C, Poelmann RE, Burch JB, Evans T: GATA-4/5/6, a subfamily of three transcription factors transcribed in developing heart and gut. J Biol Chem 1994, 269(37):23177-23184.

68. Maeda M: Gastric proton pump ( $\mathrm{H}+/ \mathrm{K}(+)-A T P a s e)$ : structure and gene regulation through GATA DNA-binding protein(s). J Biochem 1994, 115(1):6-14.

69. Britton C, McKerrow JH, Johnstone IL: Regulation of the Caenorhabditis elegans gut cysteine protease gene $c p r-1$ : requirement for GATA motifs. J Mol Biol 1998, 283(1):15-27.

70. McGhee JD, Fukushige T, Krause MW, Minnema SE, Goszczynski B, Gaudet J, Kohara Y, Bossinger O, Zhao Y, Khattra J, Hirst M, Jones SJ, Marra MA, 
Ruzanov P, Warner A, Zapf R, Moerman DG, Kalb JM: ELT-2 is the predominant transcription factor controlling differentiation and function of the C. elegans intestine, from embryo to adult. Dev Biol 2009, 327(2):551-565.

71. McKay SJ, Johnsen R, Khattra J, Asano J, Baillie DL, Chan S, Dube N, Fang L, Goszczynski B, Ha E, Halfnight E, Hollebakken R, Huang P, Hung K, Jensen V, Jones SJ, Kai H, Li D, Mah A, Marra M, McGhee J, Newbury R, Pouzyrev A, Riddle DL, Sonnhammer E, Tian H, Tu D, Tyson JR, Vatcher G, Warner A, et al: Gene expression profiling of cells, tissues, and developmental stages of the nematode C. elegans. Cold Spring Harb Symp Quant Biol 2003, 68:159-169.

72. Hunt-Newbury R, Viveiros R, Johnsen R, Mah A, Anastas D, Fang L, Halfnight E, Lee D, Lin J, Lorch A, McKay S, Okada HM, Pan J, Schulz AK, Tu D, Wong K, Zhao Z, Alexeyenko A, Burglin T, Sonnhammer E, Schnabel R, Jones SJ, Marra MA, Baillie DL, Moerman DG: High-throughput in vivo analysis of gene expression in Caenorhabditis elegans. PLoS Biol 2007, 5(9):e237.

73. Kimble J, Sharrock WJ: Tissue-specific synthesis of yolk proteins in Caenorhabditis elegans. Dev Biol 1983, 96(1):189-196.

74. Schulenburg H, Kurz CL, Ewbank JJ: Evolution of the innate immune system: the worm perspective. Immunol Rev 2004, 198:36-58.

75. Pauli F, Liu Y, Kim YA, Chen PJ, Kim SK: Chromosomal clustering and GATA transcriptional regulation of intestine-expressed genes in C. elegans. Development 2006, 133(2):287-295.

76. McGhee JD: The C. elegans intestine. In WormBook. 2007:1-36.

77. Zhu J, Hill RJ, Heid PJ, Fukuyama M, Sugimoto A, Priess JR, Rothman JH: End-1 encodes an apparent GATA factor that specifies the endoderm precursor in Caenorhabditis elegans embryos. Genes Dev 1997, 11(21):2883-2896.

doi:10.1186/s13071-014-0561-z

Cite this article as: Yuan et al:: Exploring features and function of Ss-riok-3, an enigmatic kinase gene from Strongyloides stercoralis. Parasites \& Vectors 2014 7:561

\section{Submit your next manuscript to BioMed Central and take full advantage of:}

- Convenient online submission

- Thorough peer review

- No space constraints or color figure charges

- Immediate publication on acceptance

- Inclusion in PubMed, CAS, Scopus and Google Scholar

- Research which is freely available for redistribution 